\title{
Role of Reversed Sural Artery Flap in Reconstruction of Lower Third of the Leg, Ankle and Foot Defects
}

\author{
Mohamed Elsayed Mohamed Mohamed*, Belal A. Al Mobarak \\ Plastic Surgery Department, Ahmed Maher Teaching Hospital, Cairo, Egypt \\ Email: *mghabn5777@yahoo.com
}

How to cite this paper: Mohamed, M.E.M. and Al Mobarak, B.A. (2018) Role of Reversed Sural Artery Flap in Reconstruction of Lower Third of the Leg, Ankle and Foot Defects. Modern Plastic Surgery, 8, 50-59. https://doi.org/10.4236/mps.2018.83007

Received: April 17, 2018

Accepted: July 6, 2018

Published: July 9, 2018

Copyright $\odot 2018$ by authors and Scientific Research Publishing Inc. This work is licensed under the Creative Commons Attribution International License (CC BY 4.0).

http://creativecommons.org/licenses/by/4.0/

(c) (i) Open Access

\begin{abstract}
Introduction: Coverage of defects of the distal lower extremity and foot remains a challenging reconstructive procedure. Free tissue transfer remains the standard for the management of these defects. However, there are some disadvantages like; longer operative times, bulky contour, and the need for highly skilled expertise. The reverse superficial sural artery flap (RSSAF) is a distally based fasciocutaneous or adipo-fascial flap that is used for coverage of defects that involve the distal third of the leg, ankle, and foot. A significant advantage of this flap is a constant blood supply that does not require sacrifice of a major artery. Methods: Twenty RSSAF flaps were harvested for reconstruction of different traumatic soft tissue defects of the lower third of leg, ankle and foot. Follow up for 6 months postoperative. Results: Twenty Patients; twelve males and eight females underwent reconstruction of different soft tissue defects over the foot and ankle using RSSAF. The overall complications occurred in 6 flaps; 4 minor and 2 major complications. The remaining 14 flaps passed an uneventful follow up. Conclusions: The reverse superficial sural artery flap RSSAF can be used as a reliable alternative to free tissue transfer in reconstruction of defects over the lower third of leg, ankle, and foot. Venous congestion is the major threat to the flap but its incidence can be minimized by wide pedicle, less kink of the flap, and keep the venae comitants around the artery.
\end{abstract}

\section{Keywords}

Leg Defects, Ankle and Dorsum of Foot, Reversed Sural Artery Flap

\section{Introduction}

Coverage of Soft-tissue defects of the distal lower extremity and foot remains a 
challenging reconstructive procedure. Unreliable blood supply and paucity of local donor tissue often preclude the use of local and regional flaps [1].

Free tissue transfer remains the standard for the management of these complicated wounds. However, even with its many advantages, it is encumbered by donor site morbidity, longer operative times, bulky contours, recipient vessel trauma, and the requirement for advanced surgical expertise and expensive equipment. Moreover, not every patient is a good candidate for prolonged general anesthesia. These issues highlight the need for locally based tissue reconstructive alternatives that are shorter in duration, easy to perform, and reliable. The RSSAF has been touted to be the ideal solution [2] [3].

The reverse superficial sural artery flap (RSSAF) is a distally based fasciocutaneous or adipo-fascial flap that is used for coverage of defects that involve the distal third of the leg, ankle, and foot. Donski and Fogdestam, in 1983 described the flap and later by the year 1992 championed by Masquelet et al. The RSSAF has become a popular option for many of these difficult wounds [4] [5].

A significant advantage of this flap is a constant blood supply that does not require sacrifice or manipulation of a major artery to the lower limb. These flaps are vascularized by septo-cutaneous perforators of the peroneal artery that anastomose with the peri-neural and peri-venous arterial networks of the sural nerve and the lesser saphenous vein, respectively [6].

However, the RSSAF is often at risk for venous congestion, as it relies on communication between the venae comitants of the sural nerve and the lesser saphenous vein, thus hinders the valves of the deep venous system [7]. This impaired venous drainage of the RSSAF may contribute to flap necrosis in the early postoperative period [7].

It has shown that flap survival was improved by various modifications to the operative technique that enhanced venous outflow of the RSSAF, and that these changes reduced the use of leech therapy [8].

Several revisions to the operative technique have been proposed since its original description almost 35 years ago [9] and the RSSAF is now considered an accepted and popular method for coverage of soft-tissue loss in the distal third of the leg, ankle, and foot from a number of etiologies [10].

Compared with other local and regional flaps, the RSSAF has a larger arc of rotation than the extensor digitorum brevis and peroneus brevis muscle flaps. [11] [12] Long periods of immobilization and difficult positioning are avoided unlike the cross-leg flap [13]. Also, the RSSAF has been shown to be significantly more reliable than the lateral supra-malleolar flap [14].

\section{Patients and Methods}

At the Plastic Surgery Department of Ahmed Maher Teaching hospital, from March 2016 to October 2017, we harvested 20 RSSAF flaps for reconstruction of different traumatic soft tissue defects of the lower third of leg, ankle and foot. The defects were either early after trauma or delayed sometime after trauma. All 
patients were admitted from out-patient clinic or emergency department, immediately following trauma. There were no costs for operative procedures nor hospital stay, as the hospital is a teaching one. Follow up was done for 6 month post-operative on a weekly basis for the first month, then monthly till the 6th month, unless there are post-operative complications (Figures 1-4).

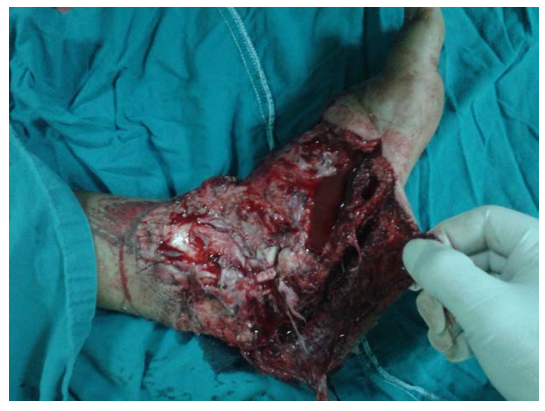

(a)

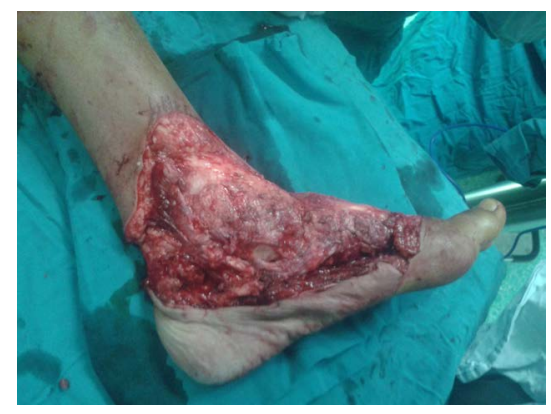

(b)

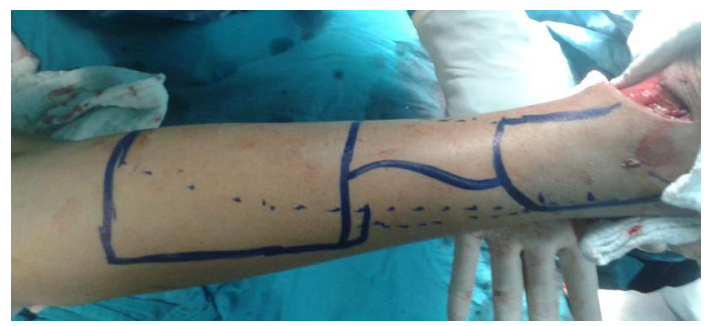

(c)

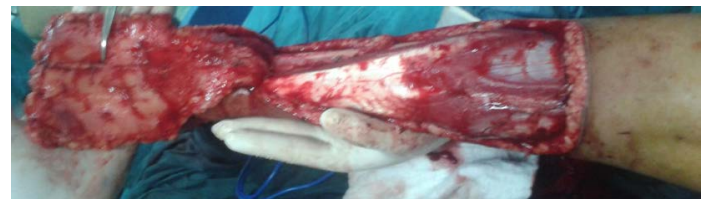

(d)

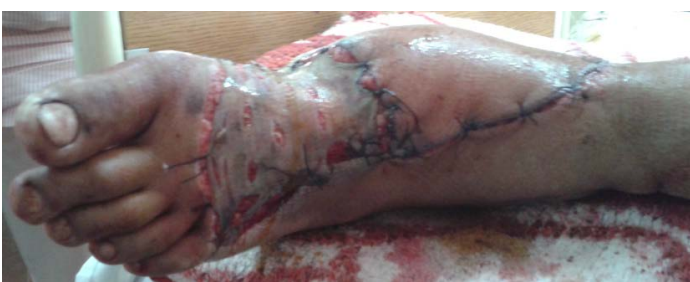

(e)

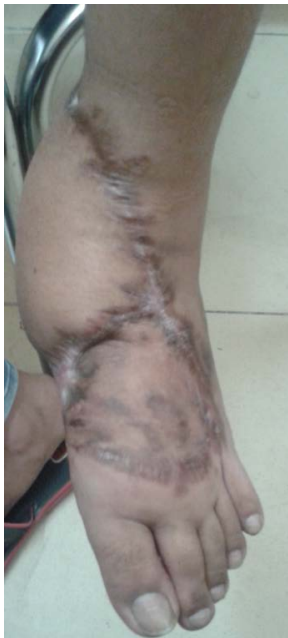

(f)

Figure 1. (a) Pre-operative view; (b) Intra-operative view, after debridement; (c) Design of the flap; (d) Elevation of the flap; (e) Early post-operative view; (f) Late post-operative view. 


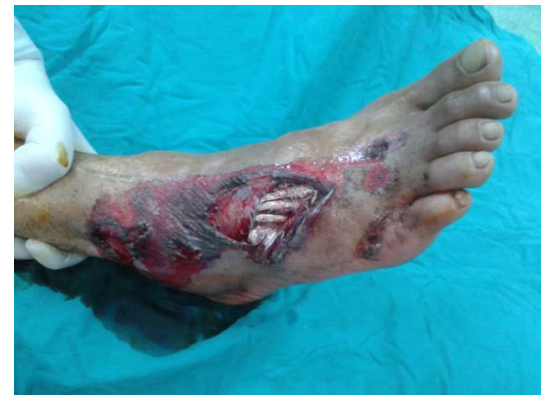

(a)

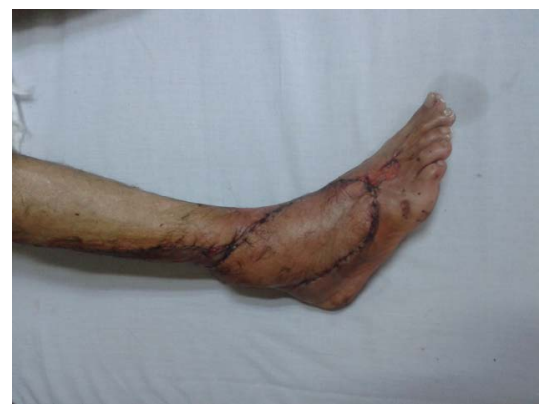

(c)

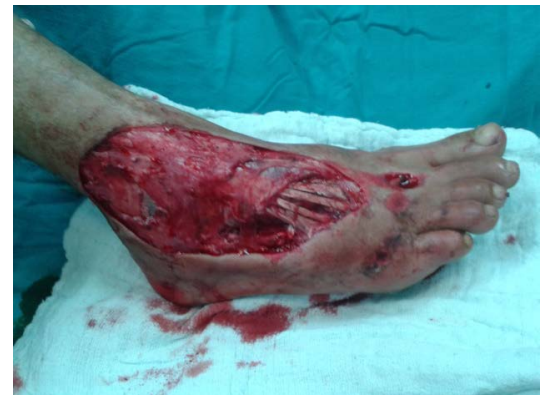

(b)

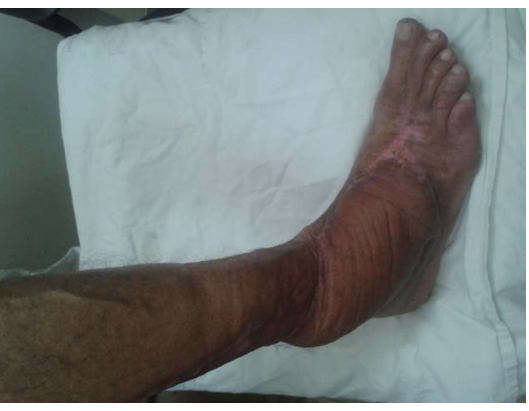

(d)

Figure 2. (a) Pre-operative view; (b) Intra-operative view, after debridement; (c) Early post-operative view; (d) Late post-operative view.

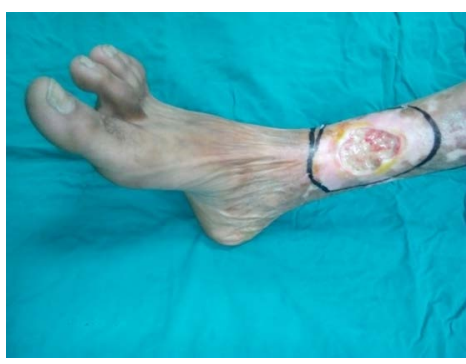

(a)

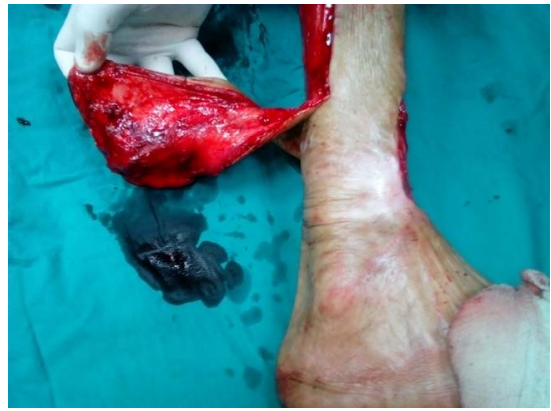

(c)

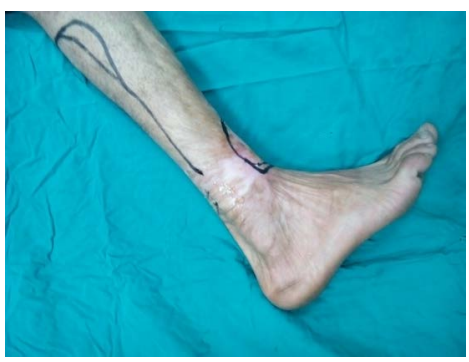

(b)

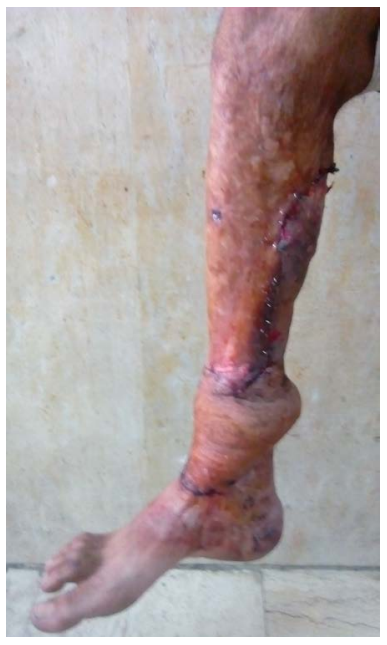

(d)

Figure 3. (a) Pre-operative view; (b) Design of the flap; (c) Intra-operative view, after flap elevation; (d) Post-operative view. 


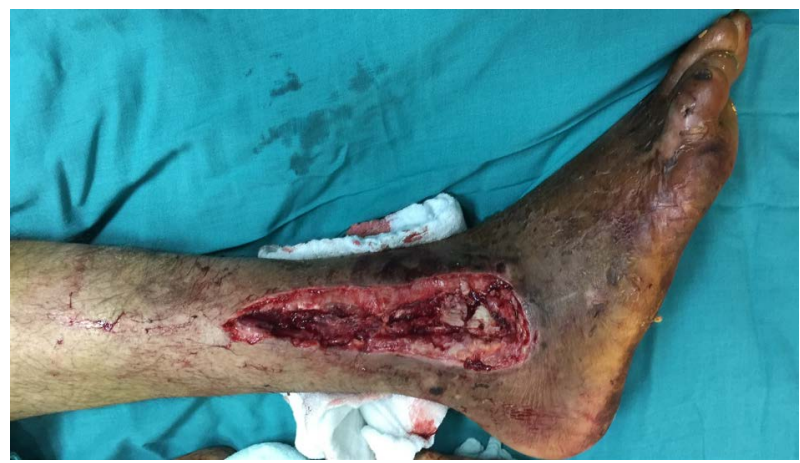

(a)

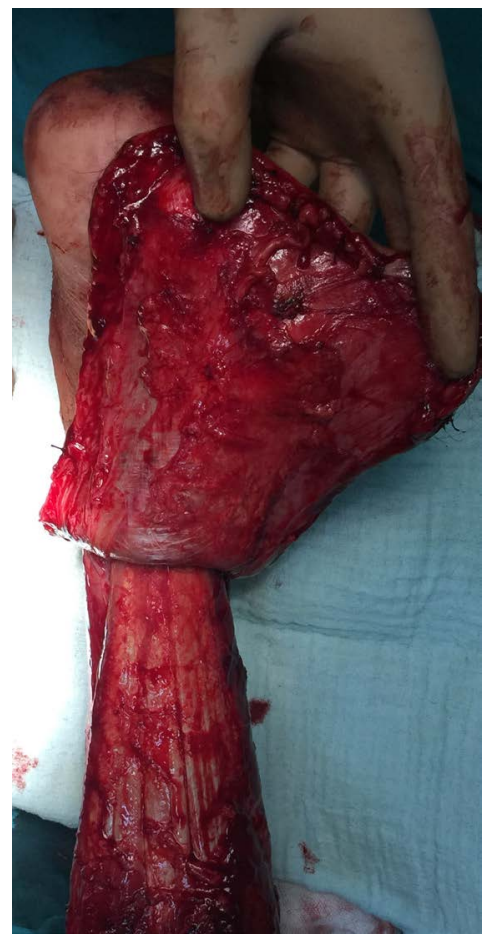

(b)

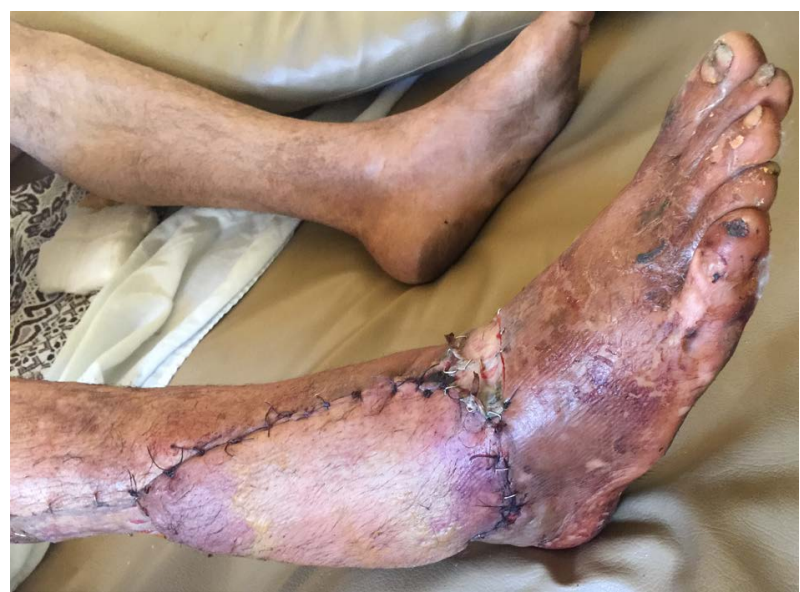

(c)

Figure 4. (a) Pre-operative view; (b) Intra-operative view, after flap elevation; (c) Post-operative view with mild flap congestion. 


\section{Surgical Technique}

The patient was placed in supine position. Debridement of the defect was done. The patient was placed in the prone position. Perforating vessels from the peroneal artery were then identified by Doppler ultrasonography along the posterolateral intermuscular septum of the lower leg. Typically 2 - 5 perforators were found at an average distance of $5-7 \mathrm{~cm}$ proximal to the lateral malleolus. A line was drawn from the popliteal fossa to the lateral malleolus to approximate the vascular axis of the flap. A template of the defect was used to position the flap along this axis, such that the distance from the chosen pivot point to the end of the flap was just greater than the distance from the pivot point to the farthest edge of the defect.

The skin was incised down to the level of the fascia. The sural nerve, median superficial sural artery, and lesser saphenous vein were ligated as part of the proximal dissection. The dissection continued down to the pedicle. The width of the pedicle was about $4 \mathrm{~cm}$. The skin between the flap pedicle and the defect was divided along the entire length of the pedicle. Next, the flap was elevated from proximal to distal in the sub-fascial plane to the level of the chosen pivot point. A portion of the intervening skin bridge between the pivot point and defect was excised to allow for transposition of the pedicle. The flap was then transferred into the defect without kinking or twisting, and the flap was inset. Finally, the skin at the donor site was closed primarily to the greatest extent possible. The remaining open wound at the donor site was covered with split-thickness skin grafts. The time of surgery ranged from $2-3$ hours.

All patients were placed in a custom posterior leg splint to relieve any external pressure on the flap and pedicle and to facilitate flap monitoring.

Postoperative period: all flaps were checked regularly during the first 2 - 3 days for any venous congestion. Dressing for the graft was done on the 7th day. Sutures removed on the 14th day. Follow up twice weekly for the first month then once weekly for the 2nd month then once monthly for the rest of the 6 months follow up duration.

Some flaps needed a second stage either for division 3 weeks after the time of the primary reconstruction or for debulking 3 months after time of reconstruction.

Complications were analyzed, a major complication was defined as necrosis and loss of any part of the flap that needed further interference (debridement and grafting), while mild venous congestion, epidermolysis leading to impairment of wound healing that could be treated conservatively was defined as a minor complication.

\section{Results}

Patient data are summarized in Table 1.

(20) Patients, (12) males and (8) females underwent reconstruction of different soft tissue defects over the foot and ankle using RSSAF. 
Table 1. Showing patient data.

\begin{tabular}{ccccccc}
\hline \multicolumn{2}{c}{ Sex } & \multicolumn{2}{c}{ Diagnosis } & \multicolumn{2}{c}{ Area reconstructed $(*)$} \\
\hline Male (n) & Female (n) & Early trauma & Chronic exposure (delayed) & leg & Ankle & Foot \\
\hline 12 & 8 & 14 & 6 & 3 & 6 & 14 \\
\hline
\end{tabular}

*The flap can cover more than one part at a time.

The average time of flap harvest was about $1-1.5$ hours. The dimensions of the flap itself (rather than the length of the pedicle which is about $4 \mathrm{~cm} \times 10 \mathrm{~cm}$ ) ranged from $(5 \mathrm{~cm}$ width $\times 10 \mathrm{~cm}$ length) up to $(10 \mathrm{~cm}$ width $\times 20 \mathrm{~cm}$ length).

The overall complications (Table 2) occurred in 6 flaps represented (30\%), 4 minor (about 20\%) in the form of mild venous congestion and epidermolysis which were treated conservatively, and 2 major (about 10\%) complication in the form of partial necrosis of the flap mostly due to severe venous congestion which needed grafting after debridement of the necrosed tissues. The remaining flaps [14] showed no complications and passed an uneventful follow up period represented $70 \%$ of the flaps.

\section{Discussion}

The distal lower extremity and foot have long been recognized as problematic areas for reconstruction because local donor tissue is often insufficient or is located within the zone of injury. Also, unreliable blood supply plays a role in difficulty of reconstruction using local and regional flaps. Goals of reconstruction are to provide stable soft-tissue coverage [2].

Microsurgical reconstruction remains the standard for the management of these complicated wounds. Even with its many advantages, there are multiple drawbacks longer operative times, potential donor site morbidity, special expensive instruments and the requisite for qualified surgeons with microsurgical experience. Moreover, not every patient is a good candidate for prolonged general anesthesia. These drawbacks pushes the surgeons towards finding alternatives that are reliable and can compete for these drawbacks [15].

During our study, The RSSA flap was used as the choice for reconstruction of defects of the lower third of the leg, ankle and foot. We harvested the flaps with length ranged from $10 \mathrm{~cm}$ up to $20 \mathrm{~cm}$ with a mean length of $15 \mathrm{~cm}$, while the width ranged from $5 \mathrm{~cm}$ up to $10 \mathrm{~cm}$ with a mean width of $7.5 \mathrm{~cm}$. Some of the flaps were used to cover more than one area.

Out of the 20 flaps, $70 \%$ showed no complications, $20 \%$ showed epidermolysis due to mild venous congestion, and only $10 \%$ showed partial necrosis.

Our results were comparable with results of Morgan et al., in 2006, who treated 15 cases with chronic ulcers using Reversed sural artery flap. They reported that complications occurred in about 33\% (13\% treated conservatively and only $20 \%$ of the cases flaps failed completely), so their success rate was about $80 \%$ after treatment of complications [16].

Also our results are comparable with the results of A. Cheema et al., in 2007, 
Table 2. The parts affected, dimensions of the flap (rather than the pedicle) and overall complications.

\begin{tabular}{|c|c|c|c|c|}
\hline Case & Sex & Parts affected & Dimensions & Complications \\
\hline 1 & M & Ankle & $5 \times 10$ & \\
\hline 2 & $\mathrm{~F}$ & Ankle and dorsum of the foot & $10 \times 15$ & \\
\hline 3 & M & Dorsum of the foot & $7 \times 20$ & $\begin{array}{l}\text { Mild venous congestion } \\
\text { and epidermolysis, } \\
\text { treated conservatively }\end{array}$ \\
\hline 4 & M & Dorsum of the foot & $8 \times 20$ & \\
\hline 5 & M & $\begin{array}{l}\text { Lower third of leg, } \\
\text { ankle and dorsum of the foot }\end{array}$ & $10 \times 20$ & \\
\hline 6 & $\mathrm{~F}$ & Dorsum of the foot & $7 \times 15$ & \\
\hline 7 & M & $\begin{array}{l}\text { Exposed plates over the } \\
\text { lower third of the leg }\end{array}$ & $7 \times 10$ & $\begin{array}{c}\text { Partial necrosis, } \\
\text { debridement and grafting }\end{array}$ \\
\hline 8 & M & Dorsum of the foot & $7 \times 15$ & \\
\hline 9 & $\mathrm{~F}$ & Ankle & $5 \times 12$ & \\
\hline 10 & M & $\begin{array}{l}\text { Exposed plates over } \\
\text { the lower third of the leg }\end{array}$ & $6 \times 10$ & $\begin{array}{l}\text { Mild venous congestion } \\
\text { and epidermolysis, } \\
\text { treated conservatively }\end{array}$ \\
\hline 11 & $\mathrm{~F}$ & Dorsum of the foot & $7 \times 15$ & \\
\hline 12 & M & Dorsum of the foot & $8 \times 15$ & $\begin{array}{l}\text { Mild venous congestion } \\
\text { and epidermolysis, } \\
\text { treated conservatively }\end{array}$ \\
\hline 13 & $\mathrm{~F}$ & Dorsum of the foot & $7 \times 15$ & \\
\hline 14 & M & Ankle & $7 \times 12$ & \\
\hline 15 & M & Dorsum of the foot & $7 \times 16$ & $\begin{array}{l}\text { Mild venous congestion and } \\
\text { epidermolysis, treated } \\
\text { conservatively }\end{array}$ \\
\hline 16 & $\mathrm{~F}$ & Ankle & & \\
\hline 17 & M & Dorsum of the foot & $7 \times 15$ & \\
\hline 18 & F & Dorsum of the foot & $6 \times 17$ & \\
\hline 19 & $\mathrm{~F}$ & Dorsum of the foot & $8 \times 15$ & $\begin{array}{c}\text { Partial necrosis, } \\
\text { debridement and grafting }\end{array}$ \\
\hline 20 & M & Dorsum of the foot & $7 \times 20$ & \\
\hline
\end{tabular}

who showed their experience in treatment of 17 cases caused by different causes (posttraumatic, post reconstruction of foot or tendo-Achilles, tumor resection and gunshots). They harvested flaps with different sizes, the smallest flap was $6 \times$ $4 \mathrm{~cm}$ and the largest was $15 \times 12 \mathrm{~cm}$, with the average size being $11 \times 7.5 \mathrm{~cm}$. During their study, only two cases (12\%) developed partial superficial necrosis, 1 case had partial wound dehiscence that needed debridement and repair, and 1 case had postoperative discharge, which subsided after removal of the calcaneal 
plate, so complications occurred only in 4 patients out of the [17].

Also, a recent meta-analysis reviewed by Follmar et al., in 2007, reported that $82 \%$ of RSSAF heal without any flap-related complications [18].

During our study, venous congestion occurred in only $25 \%$ of cases, all of them were treated conservatively. These results disagree with the results of Kristoffer, in 2015 who reviewed treatment of 27 patients using RSSAF. Those 27 patients were divided into 2 groups early group before 2004 (15 patients), and a late group after 2004 (12 patients) and reported the rate of venous congestion is very high between patients treated with RSSAF. During their study, venous congestion occurred in $75 \%$ and $67 \%$ in both groups respectively [19].

From all the previous results and other similar studies, we found that RSSAF can be harvested to cover defects over the lower third of the leg, ankle and foot. The flap is easy to harvest, can cover large areas, with good reliability, and low rate of complications. The flap can be used as a good reliable alternative for free tissue transfer in reconstruction of the difficult defects over the lower third of the leg, ankle, and foot.

\section{Conclusion}

The reverse superficial sural artery flap RSSAF can be used as a reliable alternative to free tissue transfer in reconstruction of defects over the lower third of leg, ankle, and foot. Venous congestion is the major threat to the flap but its incidence can be minimized by wide pedicle, less kink of the flap, involvement of the lesser saphenous vein in the flap and keep the venae comitants around the artery.

\section{References}

[1] Ong, Y.S. and Levin, L.S. (2010) Lower Limb Salvage in Trauma. Plastic and Reconstructive Surgery, 125, 582-588. https://doi.org/10.1097/PRS.0b013e3181c82ed1

[2] Heller, L. and Levin, L.S. (2001) Lower Extremity Microsurgical Reconstruction. Plastic and Reconstructive Surgery, 108, 1029-1041. https://doi.org/10.1097/00006534-200109150-00036

[3] Zenn, M.R. and Levin, L.S. (2000) Microvascular Reconstruction of the Lower Extremity. Seminars in Surgical Oncology, 19, 272-281. https://doi.org/10.1002/1098-2388(200010/11)19:3<272::AID-SSU9>3.0.CO;2-F

[4] Donski, P.K. and Fogdestam, I. (1983) Distally Based Fasciocutaneous Flap from the Sural Region. A Preliminary Report. Scandinavian Journal of Plastic and Reconstructive Surgery, 17, 191-169. https://doi.org/10.3109/02844318309013118

[5] Masquelet, A.C., Romana, M.C. and Wolf, G. (1992) Skin Island Flaps Supplied by the Vascular Axis of the Sensitive Superficial Nerves: Anatomic Study and Clinical Experience in the Leg. Plastic and Reconstructive Surgery, 89, 1115-1121. https://doi.org/10.1097/00006534-199206000-00018

[6] Jolly, G.P. and Zgonis, T. (2004) Soft Tissue Reconstruction of the Foot with a reverse Flow Sural Artery Neurofasciocutaneous Flap. Ostomy Wound Management, 50, 44-49.

[7] Imanishi, N., Nakajima, H., Fukuzumi, S., et al. (1999) Venous Drainage of the Dis- 
tally Based Lesser Saphenous-Sural Veno-Neuroadipofascial Pedicled Fasciocutaneous Flap: A Radiographic Perfusion Study. Plastic and Reconstructive Surgery, 103, 494-498. https://doi.org/10.1097/00006534-199902000-00020

[8] Francesco, G., Kolker, D. and Michael, H.R. (2007) Modified Reverse Sural Artery Flap with Improved Venous Outflow in Lower-Leg Reconstruction. Annals of Plastic Surgery, 59, 563-565. https://doi.org/10.1097/01.sap.0000258452.55695.aa

[9] Hollier, L., Sharma, S., Babigumira, E., et al. (2002) Versatility of the Sural Fasciocutaneous Flap in the Coverage of Lower Extremity Wounds. Plastic and Reconstructive Surgery, 110, 1673-1679. https://doi.org/10.1097/00006534-200212000-00008

[10] Foran, M.P., Schreiber, J., Christy, M.R., et al. (2008) The Modified Reverse Sural Artery Flap Lower Extremity Reconstruction. The Journal of Trauma: Injury, Infection, and Critical Care, 64, 139-143. https://doi.org/10.1097/01.ta.0000240981.24052.e9

[11] Eren, S., Ghofrani, A. and Reifenrath, M. (2001) The Distally Pedicled Peroneus Brevis Muscle Flap: A New Flap for the Lower Leg. Plastic and Reconstructive Surgery, 107, 1443-1448. https://doi.org/10.1097/00006534-200105000-00020

[12] Pai, C.H., Lin, G.T., Lin, S.Y., et al. (2000) Extensor Digitorum Brevis Rotational Muscle Flap for Lower Leg and Ankle Coverage. The Journal of Trauma, 49, 1012-1016. https://doi.org/10.1097/00005373-200012000-00006

[13] Barclay, T.L., Sharpe, D.T. and Chisholm, E.M. (1983) Cross-Leg Fasciocutaneous Flaps. Plastic and Reconstructive Surgery, 72, 843-847. https://doi.org/10.1097/00006534-198312000-00021

[14] Touam, C., Rostoucher, P., Bhatia, A., et al. (2001) Comparative Study of Two Series of Distally Based Fasciocutaneous Flaps for Coverage of the Lower One-Fourth of the Leg, the Ankle, and the Foot. Plastic and Reconstructive Surgery, 107, 383-392. https://doi.org/10.1097/00006534-200102000-00013

[15] Saint-Cyr, M., Wong, C., Buchel, E.W., et al. (2012) Free Tissue Transfers and Replantation. Plastic and Reconstructive Surgery, 130, 858e-878e. https://doi.org/10.1097/PRS.0b013e31826da2b7

[16] Morgan, K., Brantigan, C.O., Field, C.J. and Paden, M. (2006) Reverse Sural Artery Flap for the Reconstruction of Chronic Lower Extremity Wounds in High-Risk Patients. The Journal of Foot and Ankle Surgery, 45, 417-423.

https://doi.org/10.1053/j.jfas.2006.09.016

[17] Cheema, T.A., Saleh, E.S. and De Carvalho, A.F. (2007) The Distally Based Sural Artery Flap for Ankle and Foot Coverage. The Journal of Foot and Ankle Surgery, 46, 40-47.

[18] Follmar, K.E., Baccarani, A., Baumeister, S.P., et al. (2007) The Distally Based Sural Flap. Plastic and Reconstructive Surgery, 119, 138e-148e. https://doi.org/10.1097/01.prs.0000259203.79909.7e

[19] Sugg, K.B., Schaub, T.A., Concannon, M.J., Cederna, P.S. and Brown, D.L. (2015) The Reverse Superficial Sural Artery Flap Revisited for Complex Lower Extremity and Foot Reconstruction. Plastic and Reconstructive Surgery. Global Open, 3, e519. 